\title{
Centrosome Amplification and Chromosomal Instability in Feline Lymphoma Cell Lines
}

\author{
Ryuta MIKI $^{1) *}$, Masaru OKUDA ${ }^{1) * * *}$, Tatsuo OIKAWA ${ }^{1)}$, Malaika WATANABE $^{1)}$, Zhiyong MA $^{1)}$, \\ Koutaro MATSUMOTO ${ }^{1)}$, Hiroyuki IWATA ${ }^{2)}$ and Hisashi INOKUMA ${ }^{1)}$ \\ ${ }^{1)}$ Laboratories of Veterinary Internal Medicine, and ${ }^{2)}$ Veterinary Hygiene, Faculty of Agriculture, Yamaguchi University, 1677-1 Yoshida, \\ Yamaguchi 753-8515, Japan
}

(Received 31 May 2003/Accepted 19 February 2004)

ABSTRACT. To evaluate the presence of centrosome amplification and the resulting chromosomal instability in cat tumors, a newly established feline lymphoma cell line and four already established feline lymphoma cell lines were examined using immunohistochemical analysis of centrosomes. The number of chromosomes were subsequently counted by metaphase spread. Moreover, to explore whether mutational inactivation of the $p 53$ gene or inactivation of the P53 protein caused by $m d m 2$ gene overexpression, occurred in the feline lymphoma cell lines, mutational analysis of the feline $p 53$ gene was carried out. The expression of feline $m d m 2$ mRNA was evaluated by reverse transcriptase-polymerase chain reaction (RT-PCR). Centrosome amplification and chromosomal instability was observed in three out of the five feline lymphoma cell lines. Of these three feline lymphoma cell lines, one had aberrations in the P53 amino-acid sequence, whereas the others had none. There was no significant difference in the expression of $m d m 2$ mRNA between peripheral blood mononuclear cells (PBMC) obtained from a normal cat and that of the five feline lymphoma cell lines. These findings indicate th at centrosome amplification also occurs in cat tumors and is strongly correlated with chromosomal instability, suggesting that the immunostaining of centrosomes could be an alternative method for the examination of the chromosomal instability. Furthermore, this study s uggests the presence of unknown mechanism that leads to the centrosome amplification in feline lymphomas.

KEY WORDS: centrosome, chromosome, feline, lymphoma, p53.

A centrosome is a major microtubule organizing center of the animal cell and plays a vital role in spindle pole formation, which is essential for balanced chromosome segregation. Centrosome amplification (more than 3 centrosomes are contained in a cell) has been frequently observed in human and dog tumors [1,32], and is thought to be a major cause of chromosomal instability [1, 19, 29]. Chromosomal instability and the resulting aneuploidy, like other types of genomic instability, is considered to be important for multistep tumorigenesis through the accumulation of alterations responsible for malignant phenotype $[15,22,30]$. Although a number of chromosomal abnormalities have been revealed in cat tumors $[9,10,42]$, the centrosome amplification has yet to be explored.

An aberration of the $p 53$ tumor suppressor gene is one of the most frequently occurring gene mutations in a variety of human and dog tumors (more than $50 \%$ in human tumors) $[14,18,33]$. It has been shown that the P53 tumor suppressor protein is involved in the regulation of the centrosome checkpoint at both the G1/S $[11,16,40]$ and the G2/M transition phases [4, 28, 36, 39] of the cell cycle, and loss or mutational inactivation of $p 53$ results in abnormal amplification of centrosomes [7, 8]. Moreover, mouse double minute 2 (MDM2) induced by P53 is known to be a negative-regulator of P53 function, and promotes P53 degradation $[12,17]$. Several types of P53 inactivation, such as

\footnotetext{
* These two authors contributed equally to this work.

**CoRRESPONDENCE TO: OKUDA, M., Laboratory of Veterinary Internal Medicine, Faculty of Agriculture, Yamaguchi University, Yamaguchi 753-8515, Japan.
}

point mutation, deletion of the $p 53$ gene, and inactivation of the P53 protein induced by overexpressed MDM2, which contributes to centrosome amplification, have been frequently observed in human and dog tumors $[1,32]$.

Neoplastic diseases, especially those occurring of the hematopoietic system, are frequently encountered in cats [38] and are one of the major problems faced by veterinarians in small animal practice. Feline leukemia virus (FeLV) infection promotes tumorigenesis in cats by the activation of the $c$-myc gene $[6,24,25]$. However, activation of the $c$ $m y c$ gene alone is not sufficient in inducing tumors [27]; these feline hematopoietic tumors may be formed through a multi-step tumorigenesis process like human colon carcinomas [5]. In mouse erythroleukemias induced by murine leukemia virus, rearrangements and retroviral insertional inactivation of the $p 53$ gene have been noted [13]. However, these types of $p 53$ aberration have not been found in feline lymphomas [26]. Furthermore, it is known that mutational inactivation of the $p 53$ gene occurs less frequently in feline lymphomas as compared to human and dog tumors [26]. Because the abrogation of P53 function is one of the most important processes in human and dog tumors, other mechanism resulting in the loss of the P53 function might be involved in feline lymphoma tumorigenesis.

Recently, it has been shown that the centrosome amplification is reduced in prolonged cell cultures [3]. Therefore, we established a new feline lymphoma cell line (R96) for use in this study. Using the R96 cell line and 4 already established cell lines, we evaluated the presence of centrosome amplification, which results in chromosomal insta- 
bility in feline lymphoma cell lines. We also examined whether p53 mutation or inactivation of P53 caused by $m d m 2$ gene overexpression occurs in the feline lymphoma cell lines.

\section{MATERIALS AND METHODS}

Cells: Tumor cells were isolated from a mix-breed cat with multicentric lymphoma that was referred to the Veterinary Hospital of Yamaguchi University. Mononuclear cells were isolated by gradient centrifugation (Lymphoprep, NYCOMED, Oslo, Norway) from the pleural effusion sample. The isolated cells were cultured in a tissue culture flask with RPMI1640 (GIBCO BRL, MD, U.S.A.) containing $10 \%$ fetal bovine serum (FBS, GIBCO BRL), and $100 \mathrm{U} / \mathrm{m} l$ Penicillin-Streptomycin (GIBCO BRL). The flask was incubated in a $37^{\circ} \mathrm{C}$ humidified chamber with $95 \%$ air and $5 \% \mathrm{CO}_{2}$. The doubling time of the R96 cells was calculated by dividing the cells into 15 wells, diluting approximately 8 $\times 10^{5}$ cells $/ \mathrm{m} l$, and counting the number of cells 5 times ( 3 , $6,9,12$ and $21 \mathrm{hr}$ ). At each counting, the R96 cells were counted 3 times, and the average was obtained. Other cell lines used in this study, KO-1 [20], 3201 [34], FT-1 [24], FL74 [21] were also cultured in the same medium as described above, and incubated under the same conditions. As a control, peripheral mononuclear cells (PBMC) were also isolated from a clinically healthy cat by gradient centrifugation, and cultured in a similar manner to the lymphoma lines.

FeLV antigen detection: FeLV virus antigen was tested from supernatant of the cell culture using Snap FeLV/FIV combo (IDEXX, ME, U.S.A.).

Indirect immunofluorescence: For all immunostaining except for co-immunostaining of $\gamma$-tubulin and $\beta$-tubulin, cells were washed three times in phosphate buffered saline (PBS, pH 7.2, 0.14 M NaCl, $2.7 \mathrm{mM} \mathrm{KCl,} 1.5 \mathrm{mM} \mathrm{KH}_{2} \mathrm{PO}_{4}$, $8.1 \mathrm{mM} \mathrm{Na} \mathrm{HPO}_{4} \bullet 12 \mathrm{H}_{2} \mathrm{O}$ ), and centrifuged on positivelycharged glass slides (Fisher Scientific, PA, U.S.A.) for 5 $\mathrm{min}$ at $250 \mathrm{~g}$ at room temperature. After centrifugation, cells were immediately fixed in $10 \%$ formalin containing $10 \%$ methanol for $20 \mathrm{~min}$ at room temperature. The cells were then washed with PBS and permeabilized with $1 \%$ Nonident P-40 (Katayama, Tokyo, Japan) in PBS for 5 min at room temperature. Cells were first incubated with blocking solution (10\% normal goat serum in PBS) for $1 \mathrm{hr}$ and then probed with mouse anti- $\gamma$-tubulin monoclonal antibody (GTU-88, Sigma, MO, U.S.A.) for $1 \mathrm{hr}$. The antigen-antibody complex was detected after incubation for $1 \mathrm{hr}$ at room temperature with Alexa Fluor 488-conjugated goat antimouse IgG antibody (Molecular Probe, OR, U.S.A.). For co-immunostaining of anti- $\gamma$-tubulin antibodies, rhodamineconjugated anti- $\gamma$-tubulin polyclonal antibody (C-20, SantaCruz, CA, U.S.A) was also used with the anti- $\gamma$-tubulin monoclonal antibody (GTU-88). The samples were washed three times with tris buffered saline (TBS, 9.9 mM tris, 0.15 $\mathrm{M} \mathrm{NaCl}$ plus pH 7.4), and then counterstained with 4', 6diamidino 2-phenylindole (DAPI) DNA dye. The number of centrosomes per cell were scored for $>300$ cells by three investigators.

For co-immunostaining of $\gamma$-tubulin and $\beta$-tubulin, cells on positively-charged glass slides were first placed on ice for $20 \mathrm{~min}$ to destabilize microtubules nucleated at the centrosomes. The cold-treated cells were then subjected to brief extraction $(10 \mathrm{sec})$ with cold extraction buffer $[0.75 \%$ Triton X-100, 5mM Pipes, 2mM EGTA (pH 6.7)], briefly washed in cold PBS, fixed and then incubated in blocking solution as described above. Cells were then incubated with rhodamine-conjugated anti- $\gamma$-tubulin polyclonal antibody (C-20) and mouse anti- $\beta$-tubulin monoclonal antibody (Tub 2.1, Sigma). The antigen-antibody complex was detected with Alexa Fluor 488-conjugated goat anti-mouse IgG antibody (Molecular Probe) for $\gamma$-tubulin.

Metaphase spread and chromosome counting: Metaphase spread was prepared as described previously [8]. Briefly, cells were incubated in the presence of $0.5 \mu \mathrm{g} / \mathrm{m} l$ colcemid (Sigma) for $2 \mathrm{hr}$ to enrich mitotic cells. The cells were pelleted by centrifugation. The cell pellet was gently resuspended in the hypotonic solution $(0.075 \mathrm{M} \mathrm{KCl})$ and allowed to stand for $10 \mathrm{~min}$ at $37^{\circ} \mathrm{C}$. After removal of hypotonic solution, a methanol-acetic acid (3:1) fixative was added, and cells were allowed to stand for $5 \mathrm{~min}$. After discarding the old fixative, fresh fixative was added. This procedure was repeated a total of three times. After the last change of fixative, a few drops were put onto a positivelycharged glass slide (Fisher Scientific) and dried completely on a $37^{\circ} \mathrm{C}$ hot plate. The dried samples were subjected to Giemsa staining and analyzed under a light microscope. For each cell line and for the control PBMC, more than 300 cells were independently examined by three investigators.

Statistical analysis: Variance ratio of the chromosome numbers of the each cell line against that of the control PBMC was obtained using the test for equal varians ( $F$ test). The correlation between the percentages of centrosome amplification and the variance ratio was examined by simple linear correlation.

Sequence analysis of the p53 gene: Total RNA was extracted (RNeasy Mini Kit, QIAGEN, Hilden, Germany), and then reverse transcribed using an oligo-dT adapter primer (AP, 3' RACE System for Rapid Amplification of cDNA ENDs kit, GIBCO BRL). For PCR amplification, primers were designed based on the sequence of the feline p53 gene [26], which covered the entire coding region. The sequences of primers used for amplifying the 5' portion were cSP53-1 (corresponding to nt. 67-85 of cat p53, GenBank accession number D26608) and cAP53-1 (nt. 755737). The 3' porton was amplified with primers, cSP53-2 (nt. 683-700) and cAP53-2 (nt. 1363-1346). The cDNA was amplified by PCR in a volume of $50 \mu l$, using each pair of primers ( $25 \mu \mathrm{M}$ each), 0.5 units of AmpliTaq Gold DNA polymerase (Applied Biosystems, CA, U.S.A.) and the reagents as recommended by the manufacturer. After the initial hot start $\left(94^{\circ} \mathrm{C}, 9 \mathrm{~min}\right)$, amplification was performed by 30 cycles of denaturation $\left(94^{\circ} \mathrm{C}, 1 \mathrm{~min}\right)$, annealing $\left(56^{\circ} \mathrm{C}, 1 \mathrm{~min}\right)$, and polymerization $\left(72^{\circ} \mathrm{C}, 1 \mathrm{~min}\right)$. The 
resulting products were subjected to direct sequencing using BigDye Terminator Cycle Sequencing Ready Reaction Kit (Amersham Pharmacia Biotech, Buckinghamshire, England). The nucleotide sequence of each fragment was determined for both DNA strands in opposite direction.

Expression of $m d m 2 m R N A$ in feline lymphoma cell lines: For the amplification of a part of feline $m d m 2$ and detection of its expression pattern in the cell lines, reverse transcription of $1 \mu \mathrm{g}$ total RNA was performed (3' RACE System for Rapid Amplification of cDNA ENDs kit, GIBCO BRL). After the initial hot start $\left(94^{\circ} \mathrm{C} 9 \mathrm{~min}\right), \mathrm{PCR}$ amplification was performed by 20 or 30 cycles of $1 \mathrm{~min}$ at $94^{\circ} \mathrm{C}, 1 \mathrm{~min}$ at $54^{\circ} \mathrm{C}$ and $1 \mathrm{~min}$ at $72^{\circ} \mathrm{C}$. For PCR, gene-specific primers, cMDMS (corresponding to nt. 747-765 of cat mdm2, GenBank accession number AB099709) and cMDMA (nt. 951933), were used. A primer pair, FBAIS (corresponding to nt. 284-307, GenBank accession number AB051104) and FBAIR (nt. 672-649) was used to amplify 389 bp feline $\beta$ actin as a control for cDNA synthesis. PBMC isolated from the blood of normal cat by gradient centrifugation was also used as a control.

\section{RESULTS}

Establishment of a new feline lymphoma cell line: Tumor cells in the pleural effusion of a cat with multicentric lymphoma were cultured. Four weeks after initiation of the culture, active proliferation of cells was observed, and the cells could be subcultured. This established cell line designated as R96, grew well in suspension with a doubling time of $31.8 \mathrm{hr}$. The R96 cells have been maintained in RPMI1640 medium with $10 \%$ FBS for more than a year.

FeLV antigen detection: FeLV antigen was detected from supernatant of R96, FT-1 and FL74 cell lines, but not from the other cell lines (KO-1 and 3201).

Centrosome amplification in feline lymphoma cell lines: To examine whether centrosome amplification is common in feline lymphoma cell lines, five feline lymphoma cell lines were immunostained for centrosomes, using anti- $\gamma$ tublin monoclonal antibody (GTU-88). The $\gamma$-tubulin is a major component of centrosomes, and immunostaining for $\gamma$-tubulin detects centrosomes throughout the cell cycle in human and murine cells $[35,44]$. Although $\gamma$-tubulin is a highly conserved protein among species, to the best of our knowledge, no study has been conducted on the immunostaining of centrosomes using anti- $\gamma$-tublin antibody in feline cells. In this study, for the examination of immunohistochemical reactivity of the anti- $\gamma$-tublin monoclonal antibody (GTU-88) in feline cells, we performed co-immunostaining with anti- $\gamma$-tublin monoclonal antibody (GTU88) and anti- $\gamma$-tubulin polyclonal antibody (C-20) using R96 cells (Fig. 1A, a-a'). The dot signals of immunostaining using each antibody were observed at the same component on or adjacent to the nuclear membrane where centrosomes are typically localized. Moreover, co-immunostaining with anti- $\gamma$-tubulin polyclonal antibody (C-20) and anti- $\beta$-tubulin monoclonal antibody (Tub 2.1) showed that most of the dot signals detected by the anti- $\gamma$-tubulin polyclonal antibody (C-20) contained two anti- $\beta$-tubulin-reactive dots representing a pair of centrioles at a high magnification (Fig. 1A, b and $\left.b^{\prime}\right)$. This confirms that these anti- $\gamma$-tubulin antibodies specifically stain the centrosomes in feline cells.

Figure 1A (c and d) shows a representative immunostaining of $\gamma$-tubulin in R96 cells. Immunohistochemical analysis with anti- $\gamma$-tubulin antibody revealed that $>30 \%$ of R96 cells and $>20 \%$ of 3201 cells contained more than 3 centrosomes, indicating noticeable centrosome amplification in these two cell lines (Fig. 1B). Approximately $10 \%$ of the FL74 cells contained more than 3 centrosomes indicating the possibility of centrosome amplification in the FL74 cell line. Like the PBMC isolated from a clinically healthy cat, KO-1 and FT-1 cells with an abnormal number of centrosomes ( $\geq 3$ centrosomes) were less common.

Chromosomal instability in the feline lymphoma cell lines: Figure 2A shows representative microphotographs of euploid, hypoploid and hyperploid chromosomes taken from the R96 cell line. In the R96 and 3201 cell lines, the number of chromosomes were extensively expanded, and deviated from the normal number $(2 \mathrm{~N}=38)$, indicating that the newly established R96 cells and 3201 cells have extensive chromosomal instability (Fig. 2B). Chromosome numbers of FL74 were moderately expanded, indicating that chromosomes were also unstable in the FL74 cell line (Fig. 2B). In the FT-1 cells, the distribution of the number of chromosomes per cell was limited in the culture (approximately $70 \%$ of FT-1 cells containing 37 chromosomes) (Fig. 2B). Furthermore, the distribution of the number of chromosomes per cell was even more limited in the KO-1 cell line (approximately $80 \%$ of KO-1 cells containing 41 chromosomes) (Fig. 2B).

Correlation between centrosome amplification and chromosomal instability: To explore the degree of chromosomal instability, the variance ratios of the chromosome numbers of each cell line against those of the control PBMC were calculated using the $F$ test. The variance ratios of R96, KO-1, 3201, FT-1 and FL74 were 12.9, 1.62, 9.81, 1.73 and 8.35, respectively, indicating that the R96, 3201 and FL74 cell lines have greater chromosomal instability compared to the control PBMC. Next, we examined the correlation between the percentages of centrosome amplification and variance ratios by simple linear correlation. A significant correlation was observed between centrosome amplification and chromosomal instability in feline lymphoma cell lines $(r=0.91$, $\mathrm{P}<0.05)$.

Sequence analysis for cat p53: PCR amplifications for the 5' portion of p53 using cSP53-1 and cAP53-1 resulted in the production of a DNA fragment of expected size in the five-lymphoma cell lines (689 bp). PCR for the 3' portion of p53 using cSP53-2 and cAP53-2 also yielded major bands of expected size (681 bp) in all cell lines. These two DNA fragments had an overlapping sequence of $73 \mathrm{bp}$. The nucleotide sequence of each DNA fragment was determined by direct sequencing. Table 1 summarizes the results of the sequence analysis for cat p53 in the five-lymphoma cell 
A
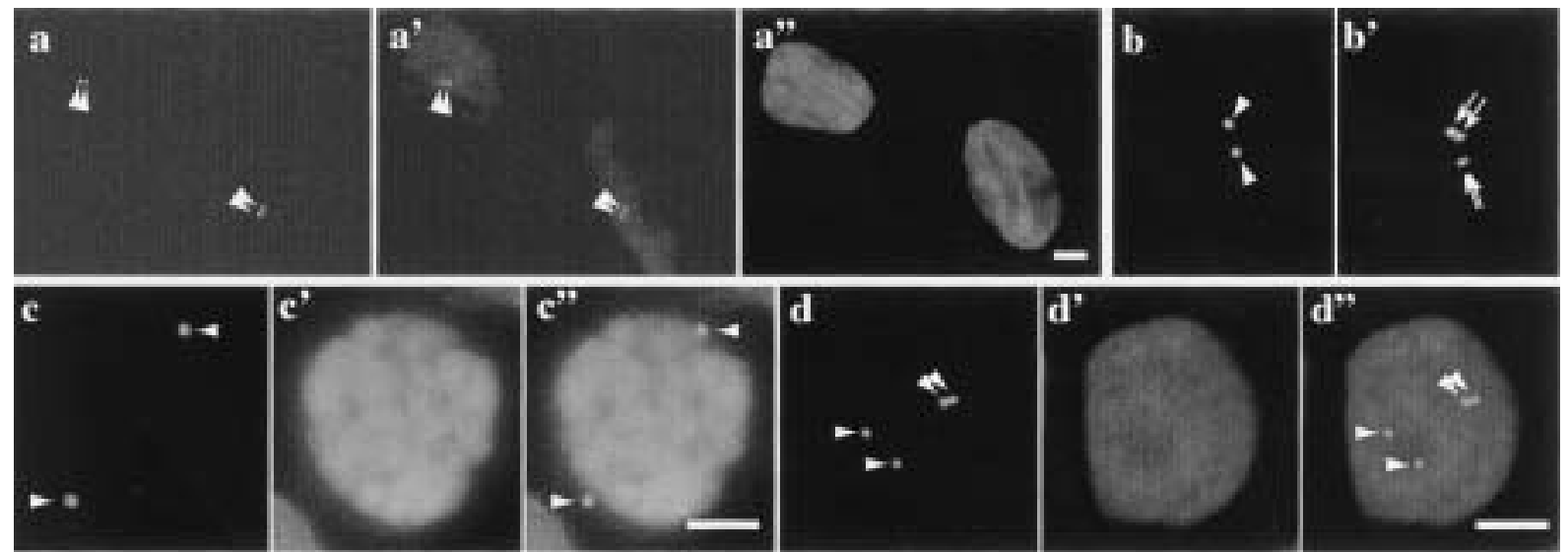

B

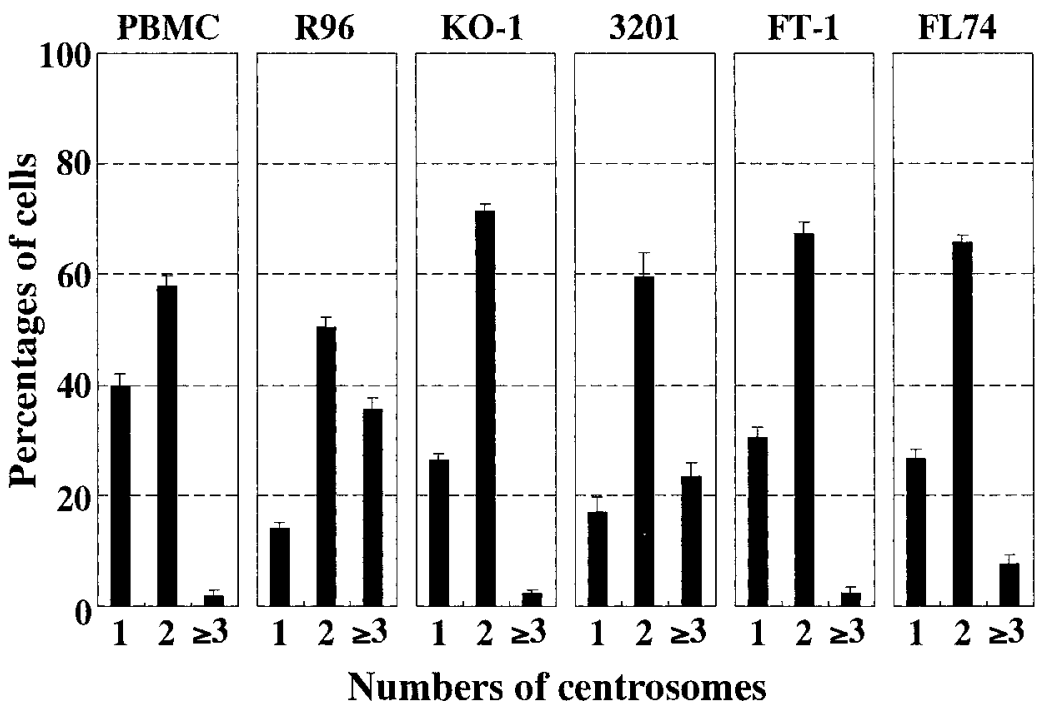

Fig. 1. Centrosome amplification in cat lymphoma cell lines. (A) Representative immunostaining of centrosomes in R96 cells. Panels a, a', and a" reveal immunostaining of centrosomes using of anti- $\gamma$-tubulin monoclonal antibody (GTU-88, Sigma), anti- $\gamma$-tubulin polyclonal antibody (C-20, SantaCruz), and DAPI DNA dye counterstain in the same microscopic field, respectively. Panels b and b' sh ow immunostaining of centrosomes with anti- $\gamma$-tubulin polyclonal antibody (C-20), and of centrioles with anti- $\beta$-tubulin monoclonal antibody (Tub 2.1, Sigma) in the same microscopic field, respectively. For centrosome counting, cells were immunostained with anti- $\gamma$ tubulin antibody (GTU-88) (panels c and d), and were also counterstained with DAPI for visualization of DNA (panels c' and d').Panels c" and d" show the overlay images of the $\gamma$-tubulin immunostainings and DAPI stainings. Panels c and d show the R96 cells which contain two and four centrosomes, respectively. Bars $=3 \mu \mathrm{m}$. Arrowheads and arrows show centrosomes and centrioles, respectively. (B) Distribution of centrosomes in clinically healthy cat PBMC and five lymphoma cell lines. Centrosome numbers of each cell was examined by immunostaining of $\gamma$-tubulin and were counted under a fluorescence microscope. At least 300 cells were examined for the control PBMC and each cell line.

lines. In the R96 cell line, there was a silent point mutation at nt. 591 (from $\mathrm{C}$ to $\mathrm{T}$ ). In the KO-1 cell line, there was a heterozygous point mutation at nt. 231 (from A to G), where guanine (mutant allele) and adenine (normal allele) waves were observed at nt. 231 (Fig. 3A). This confirms the fact that direct sequencing as used in this study can detect mutations on both alleles. In the 3201 cell line, there was a missense point mutation resulting in a substitution of cysteine ${ }^{235}$ for alanine without heterozygosity (Fig. 3B), as has been previously reported [26]. In the FT-1 cell line, there was a silent point mutation at nt. 591 (from C to T), and in FL74 cell line, there were three silent point mutations at nt. 231 (from A to G, heterozygous), nt. 591 (from C to T) and nt. 1176 (from G to A). All the lymphoma cell lines used in this study had a genetic mutation of $p 53$, but the 3201 lymphoma cell line had a substitution of the amino-acid sequence.

Expression of $m d m 2 m R N A$ in feline lymphoma cell lines: In the 30 cycle amplification, as shown in Fig. 4A, bands 
A
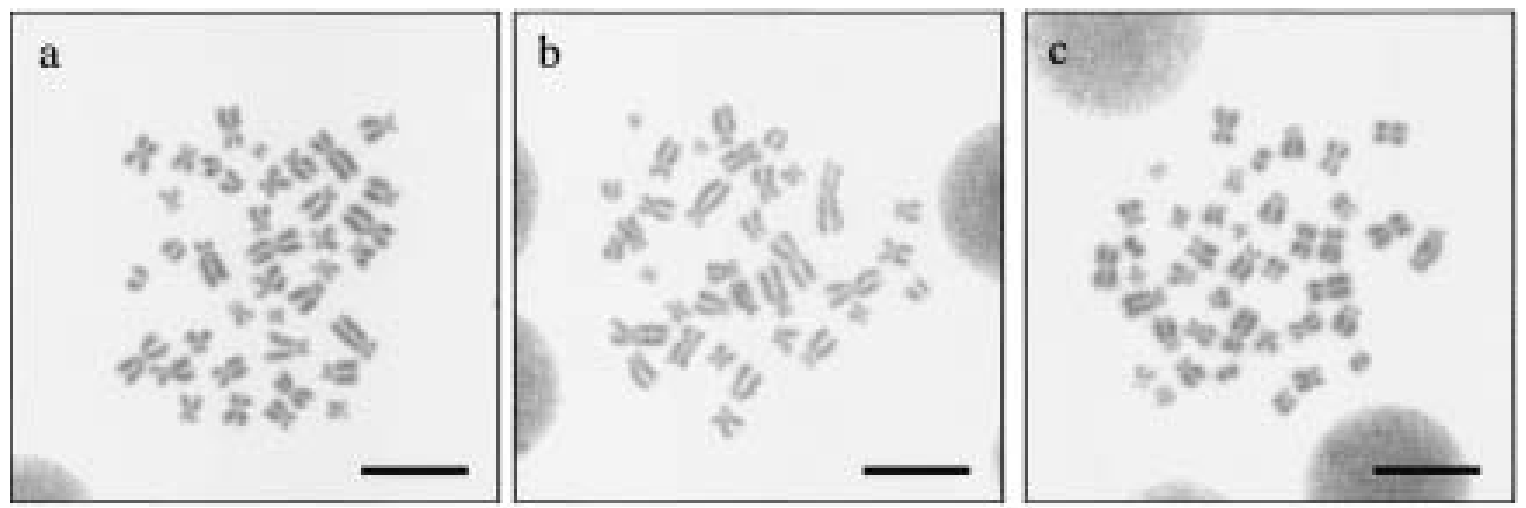

B

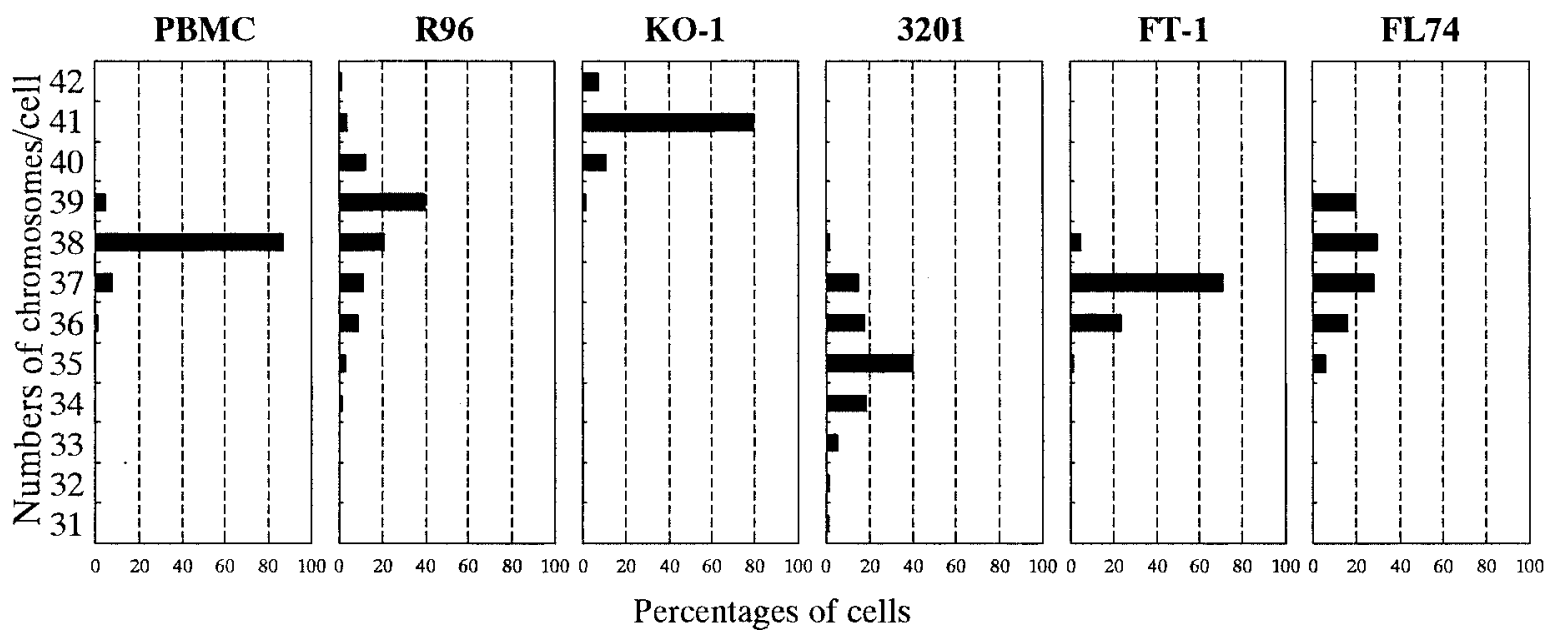

Fig. 2. Chromosomal instability in cat lymphoma cell lines. (A) Representative metaphase spreads from R96 cells. Metaphase spreads were prepared from R96 cells, stained with Giemsa, and examined under a light microscope. Panel a shows a typical euploid spread $(2 \mathrm{~N}=38)$. Panel b shows a typical hypoploid spread $(2 \mathrm{~N}=35)$. Panel $\mathrm{c}$ shows a typical hyperploid spread $(2 \mathrm{~N}=40)$. Bars $=5 \mu \mathrm{m}$. $(\mathrm{B})$ Distribution of chromosomes in clinically healthy cat PBMC and five lymphoma cell lines. Metaphase cells, enriched by treatmentof colcemid for $2 \mathrm{hr}$, were harvested and metaphase chromosome spreads were prepared. The Giemsa-stained chromosomes were directly analyzed under a light microscope. At least 300 metaphase spreads were examined for the control PBMC and each cell line.

Table 1. Mutations of $p 53$ cDNA in 5 lymphoma cell lines

\begin{tabular}{|c|c|c|}
\hline \multirow[b]{2}{*}{ Cell lines } & \multicolumn{2}{|c|}{ Mutations } \\
\hline & Nucleotides & Amino acids \\
\hline R96 & $\mathrm{TAC} \rightarrow \mathrm{TAT}$ & $\operatorname{Tyr}^{155} \rightarrow \operatorname{Tyr}$ (silent) \\
\hline KO-1 & $\begin{array}{r}\mathrm{GAA}^{\mathrm{a})} \rightarrow \mathrm{GAG} \\
\text { GAA }\end{array}$ & Glu $^{35} \rightarrow$ Glu (silent) \\
\hline 3201 & $\mathrm{TGC} \rightarrow \mathrm{CGC}$ & $\mathrm{Cys}^{235} \rightarrow$ Ala \\
\hline FT-1 & $\mathrm{TAC} \rightarrow \mathrm{TAT}$ & $\mathrm{Tyr}^{155} \rightarrow \mathrm{Tyr}$ (silent) \\
\hline FL74 & $\begin{array}{c}\mathrm{GAA}^{\mathrm{a})} \rightarrow \mathrm{GAG} \\
\text { GAA }\end{array}$ & Glu $^{35} \rightarrow$ Glu (silent) \\
\hline & $\mathrm{TAC} \rightarrow \mathrm{TAT}$ & $\mathrm{Tyr}^{155} \rightarrow \mathrm{Tyr}$ (silent) \\
\hline & $\mathrm{AAG} \rightarrow \mathrm{AAA}$ & Lys $^{350} \rightarrow$ Lys (silent) \\
\hline
\end{tabular}

a) Heterozygous. derived from $m d m 2$ mRNA were clearly detected in the control cells isolated from a healthy cat and in all lymphoma cell lines. There were no differences in the depth of bands among the control cells and the lymphoma cell lines. In the amplification of 20 cycles, very faint bands derived from $m d m 2$ mRNA were detected in both the control and the five lymphoma cell lines (Fig. 4B). There were also no differences in the depth of bands among the control and the lymphoma cell lines. The data suggest that none of the lymphoma cell lines used in this study were accompanied by MDM2 overexpression, which could contribute to inactivation of P53. 


\section{DISCUSSION}

Chromosomal instability is frequently observed in a variety of human cancers and has been shown to correlate with the acquisition of malignant phenotypes [2]. Centrosome amplification, and the resulting increase in the frequency of aberrant mitoses, is a major cause of chromosomal instabil-

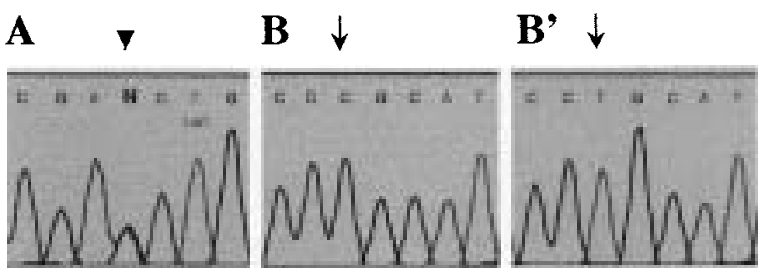

Fig. 3. Analysis of $p 53$ gene sequences in feline lymphoma cell lines. A. Heterozygous sequences of $p 53$ gene of R96 cell line. Waves of adenine and guanine are observed at nt. 591 (an arrow head), showing that mutation occurs in one allele. B. Point mutation of $p 53$ gene of 3201 cell line. A point mutation is indicated by an arrow (B) compaired with the wild-type sequence (B'). ity in human cancers $[1,19,29]$. Centrosome amplifications were observed in the R96, 3201 and FL74 lymphoma cell lines (Fig. 1B \& Table 2). To the best of our knowledge, this is the first report of centrosome amplification in cat tumors. Moreover, chromosome instabilities were also observed in the R96, 3201 and FL74 lymphoma cell lines (Fig. 2B \& Table 2). In contrast, the KO-1 and FT-1 cell lines showed no difference in the magnitude of centrosome amplification or chromosomal instability as compared to PBMC isolated from a clinically healthy cat (Table 2). Statistical analysis revealed that a strong correlation exists between centrosome amplification and chromosomal instability in feline lymphoma cells. In order to perform metaphase spreads, the method for counting the chromosome-number per cell, there is a need to culture tumor cells in order to increase number of the mitotic cells. In contrast, immunostaining for centrosomes is easy to perform on a routine clinical basis as compared to the metaphase spreads. The strong correlation between centrosome amplification and chromosomal instability indicates that centrosome immunostaining may be an alternative method for the exam-

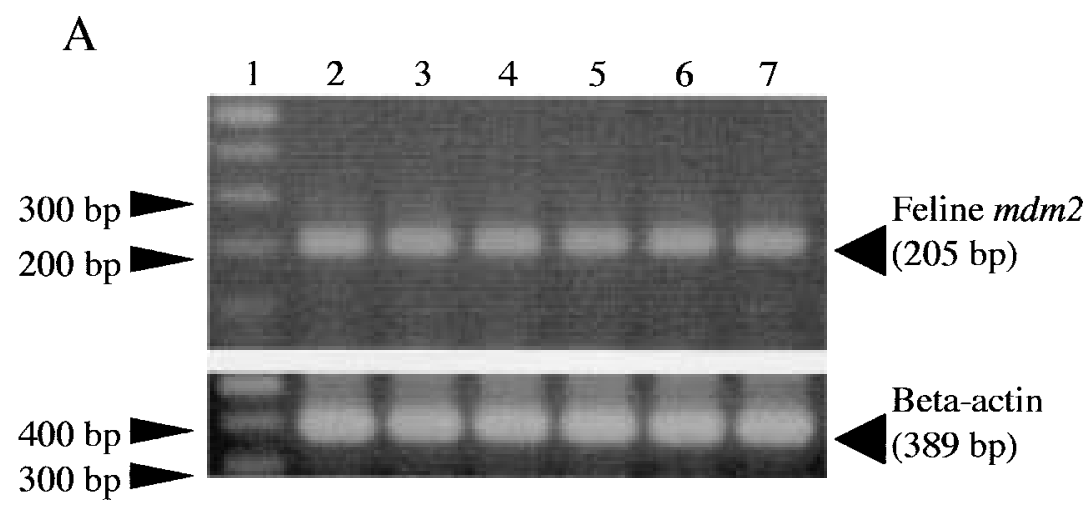

$\mathrm{B}$

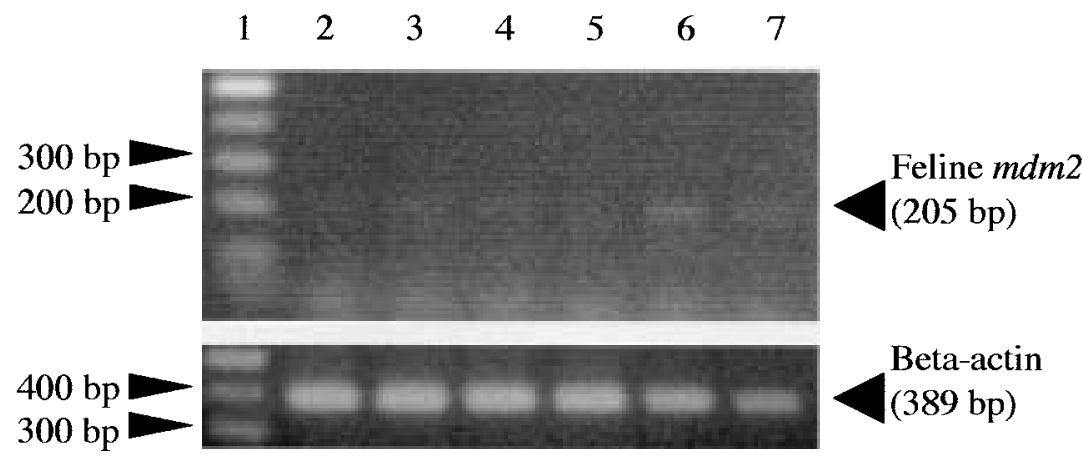

Fig. 4. RT-PCR analysis for $m d m 2$ mRNA. Reverse transcription of $1 \mu \mathrm{g}$ RNA samples extracted from control PBMC and five lymphoma cell lines was performed. PCR amplifications were performed by 30 cycles (Panel A) and 20 cycles (Panel B) of denaturation (1 $\left.\min 94^{\circ} \mathrm{C}\right)$, annealing $\left(1 \min 54^{\circ} \mathrm{C}\right)$ and polymerization $\left(1 \min 72^{\circ} \mathrm{C}\right)$, after an initial hot start $\left(9 \mathrm{~min} 94^{\circ} \mathrm{C}\right)$. Feline $\beta$-actin cDNA was also amplified for each amplification cycle as a control. Lane number 1-7 indicates DNA ladder, PBMC, R96, KO-1, 3201, FT-1 and FL74, respectively. 
Table 2. Centrosome hyperamplification and $p 53$ mutation in feline lymphoma cell lines

\begin{tabular}{|c|c|c|c|c|c|}
\hline Cell line & Centrosome & Chromosome (mean $\pm \mathrm{SD}$ ) & $p 53^{*}$ & $m d m 2$ & FeLV antigen \\
\hline R96 & ++ & $38.33 \pm 1.41$ & - & - & + \\
\hline KO-1 & - & $40.98 \pm 0.43$ & - & - & - \\
\hline 3201 & ++ & $34.94 \pm 1.24$ & + & - & - \\
\hline FT-1 & - & $36.75 \pm 0.56$ & - & - & + \\
\hline FL74 & + & $37.50 \pm 1.09$ & - & - & + \\
\hline
\end{tabular}

* Mutations with amino-acid substitutions.

ination of chromosomal instability, which is correlated with malignant phenotypes [2].

In this study, we examined the correlation between centrosome amplification, p53 mutation and inactivation of P53 caused by $m d m 2$ overexpression. RT-PCR analysis revealed the absence of $m d m 2$ mRNA overexpression in all the cell lines (see below). In the 3201 cell line, mutational inactivation of $p 53$, and centrosome amplification as well as chromosomal instability, was detected. This indicates that inactivation of P53 was caused by gene mutations which resulted in centrosome amplification in the cell lines (Table 2). These observations suggest that the aberration of P53 function also lead to centrosome amplification and chromosomal instability in cat tumors as in human and dog tumors. In contrast, no change was observed in the predicted aminoacid sequence of $p 53$ cDNA in the KO- 1 and FT- 1 cell lines, and no difference in the magnitude of centrosome amplification or chromosomal instability as compared to PBMC isolated from a clinically healthy cat was observed (Table 2). As for the 3201, KO-1 and FT-1 cell lines, the observations were consistent with previous studies showing that centrosome amplification and the resulting chromosomal instability are associated with the loss of functional P53 [7, 8, 41].

Interestingly, the newly established R96 cell line and FL74 cell line had no amino-acid substitution of P53, but showed significant centrosome amplification and obvious chromosomal instability (Table 2). The results of RT-PCR for $m d m 2$ also showed that expression levels of $m d m 2$ mRNA in the cell lines were not any different from PBMC isolated from a healthy cat and other lymphoma cell lines. Therefore it can be concluded that overexpression of $m d m 2$ did not occur in the R96 and FL74 cells. No expression of MDM2 protein was detected in the R96 and FL74 cells, the other cell lines or the control cells as determined by immunostaining for feline MDM2 using polyclonal antibody against the C-terminal of human MDM2 which is very similar to the amino-acid sequence of feline $m d m 2$ (data not shown). Eventually, noticeable centrosome amplification and chromosomal instability were observed in the R96 and FL74 cells, although both mutational inactivation of p53 and inactivation of P53, mediated by MDM2 overexpression did not occur. There are two possibilities to explain this phenomenon: (1) unknown multiple factors may be involved in centrosome homeostasis apart from P53 functions, or (2) unknown mechanisms related with P53 functions are in play, such as inactivation of downstream targets of P53 other than MDM2, or the inactivation of P53 by P53 associated proteins which inhibit P53 function. As for the second possibility, it has been revealed that some viral proteins such as SV 40 large $\mathrm{T}$ antigen, adenoviral E1B and human papilloma viral E6, bind to P53 and inactivate the functional P53 [23, 31, 43]. Because the R96 and FL74 cells produce $\mathrm{FeLV}$, it is possible that the viral proteins may bind to P53 and inactivate the functional P53. Clonal integration of proviral FeLV at the loci of proto-oncogenes and common integration regions such as $c-m y c$, flvi-2 (bmi-1), fit-1 and pim- 1 have been shown to be associated with the development of cat lymphomas [25, 37]. The myc gene is frequently activated by $\operatorname{FeLV}(32 \%)$ either by transduction or by proviral insertion [37]. However, the activation of the myc gene alone is not sufficient in inducing the tumors, strongly suggesting a multistep process of FeLV leukemogenesis [27]. It has been seen that the aberration of $p 53$ occurs less frequently in spontaneous cat lymphomas as compared to tumors in humans and dogs [26]. These observations may suggest that the viral protein produced by FeLV binds to P53 and is associated with tumorigenesis in cat lymphomas. It seems that FT-1 cells retaining the wild type of P53 and showing normal centrosome behavior inspite of FeLV infection may be contradictory to this hypothesis. However, the FT-1 cell line was established more than 20 years ago [24], and thus, chromosomal instability may have been reduced during the long term cell culturing process. The hypothesis is currently under investigation in our laboratory.

In this study, we found mutations of $p 53$ with and without amino-acid substitutions in all the five feline lymphoma cell lines examined. It is known that the aberration of p53 occurs less frequently in spontaneous cat lymphoma [26]. These findings strongly support the possibility of p53 mutations, which were derived from the long term cell culturing. Actually, the aberrations of p53 in the lymphoma cell lines were rather similar in each cell line (Table 1). The data suggest that further analyses are necessary to examine the correlation between the aberration of P53 and centrosome amplification using spontaneous cat lymphomas.

In conclusion, through this study it can be seen that centrosome amplification occurs in cat lymphoma cell lines and is strongly correlated with chromosomal instability. It was also revealed that centrosome immunostaining may be an alternative method for the examination of chromosomal instability, which in turn is correlated with malignant phenotypes. Furthermore, in this study it was observed that 
centrosome amplification occurred despite none of p53 mutations involving amino-acid substitution or inactivation of P53 mediated by MDM2 overexpression. It is of great importance to further elucidate the molecular linkage between P53 functions, FeLV proteins and other proteins, which might be involved in centrosome homeostasis, using spontaneous cat lymphomas.

ACKNOWLEDGMENTS. The authors greatly acknowledge the assistance of Dr. Hajime Tsujimoto and Dr. Koichi Ohno for providing the cat lymphoma cell lines. This work was supported in part by grants from the Ministry of Education, Science, Sports and Culture in Japan (13760221).

\section{REFERENCES}

1. Carroll, P. E., Okuda, M., Horn, H. F., Biddinger, P., Stambrook, P. J., Gleich, L. L., Li, Y. Q. and Fukasawa, K. 1999. Centrosome hyperamplification in human cancer: chromosomal instability induced by p53 mutation and/or Mdm2 overexpression. Oncogene 18: 1935-1944.

2. Cheng, K. C. and Loeb, L. A. 1993. Genomic instability and tumor progression: mechanistic considerations. Adv. Cancer Res. 60: 121-156.

3. Chiba, S., Okuda, M., Mussman, J. G. and Fukasawa, K. 2000. Genomic convergence and suppression of centrosome hyperamplification in primary p53-/- cells in prolonged culture. Exp. Cell Res. 258: 310-321.

4. Cross, S. M., Sanchez, C. A., Morgan, C. A., Schimke, M. K., Ramel, S., Idzerda, R. L., Raskind, W. H. and Reid, B. J. 1995. A p53-dependent mouse spindle checkpoint. Science 267: 1353-1356.

5. Fearon, E. R. and Vogelstein, B. 1990. A genetic model for colorectal tumorigenesis. Cell 61: 759-767.

6. Forrest, D., Onions, D., Lees, G. and Neil, J. C. 1987. Altered structure and expression of c-myc in feline T-cell tumours. Virology 158: 194-205.

7. Fukasawa, K., Choi, T., Kuriyama, R., Rulong, S. and Vande Woude, G. F. 1996. Abnormal centrosome amplification in the absence of p53. Science 271: 1744-1747.

8. Fukasawa, K., Wiener, F., Vande Woude, G. F. and Mai, S. 1997. Genomic instability and apoptosis are frequent in p53 deficient young mice. Oncogene 15: 1295-1302.

9. Grindem, C. B. and Buoen, L. C. 1989. Cytogenetic analysis in nine leukaemic cats. J. Comp. Pathol. 101: 21-30.

10. Gulino, S. E. 1992. Chromosome abnormalities and oncogenesis in cat leukemias. Cancer Genet. Cytogenet. 64: 149-157.

11. Hartwell, L. H. and Kastan, M. B. 1994. Cell cycle control and cancer. Science 266: 1821-1828.

12. Haupt, Y., Maya, R., Kazaz, A. and Oren, M. 1997. Mdm2 promotes the rapid degradation of p53. Nature (Lond.) 387: 296299.

13. Hicks, G. G. and Mowat, M. 1988. Integration of Friend murine leukemia virus into both alleles of the p53 oncogene in an erythroleukemic cell line. J. Virol. 62: 4752-4755.

14. Hollstein, M., Sidransky, D., Vogelstein, B. and Harris, C. C. 1991. p53 mutations in human cancers. Science 253: 49-53.

15. Kastan, M. B. 1997. Genetic instability and tumorigenesis: introduction. Curr. Top. Microbiol. Immunol. 221: 1-4.

16. Kastan, M. B., Canman, C. E. and Leonard, C. J. 1995. P53, cell cycle control and apoptosis: implications for cancer. Can- cer Metastasis Rev. 14: 3-15.

17. Kubbutat, M. H., Jones, S. N. and Vousden, K. H. 1997. Regulation of p53 stability by Mdm2. Nature (Lond.) 387: 299-303.

18. Levine, A. J., Momand, J. and Finlay, C. A. 1991. The p53 tumour suppressor gene. Nature (Lond.) 351: 453-456.

19. Lingle, W. L., Lutz, W. H., Ingle, J. N., Maihle, N. J., Salsbury, J. L. 1998. Centrosome hypertrophy in human breast tumors: implications for genomic stability and cell polarity. Proc. Natl. Acad. Sci. U. S. A. 95: 2950-2955.

20. Ma, Z., Khatlani, T. S., Li, L., Sasaki, K., Okuda, M., Inokuma, H. and Onishi, T. 2001. Molecular cloning and expression analysis of feline melanoma antigen (MAGE) obtained from a lymphoma cell line. Vet. Immunol. Immunopathol. 83: 241252.

21. McCarty, J. M. and Grant, C. K. 1983. Feline cytotoxic immune mechanisms against virus-associated leukemia and fibrosarcoma. Cell. Immunol. 81: 157-168.

22. Micale, M. A., Mohamed, A., Sakr, W., Powell, I. J. and Wolman, S. R. 1992. Cytogenetics of primary prostatic adenocarcinoma. Clonality and chromosomal instability. Cancer Genet. Cytogenet. 61: 165-173.

23. Michalovitz, D., Halevy, O. and Oren, M. 1990. Conditional inhibition of transformation and of cell proliferation by a temperature-sensitive mutant of p53. Cell 62: 671-680.

24. Miura, T., Shibuya, M., Tsujimoto, H., Fukasawa, M. and Hayami, M. 1989. Molecular cloning of a feline leukemia provirus integrated adjacent to the c-myc gene in a feline T-cell leukemia cell line and the unique structure of its long terminal repeat. Virology 169: 458-461.

25. Miura, T., Tsujimoto, H., Fukasawa, M., Ohta, Y., Honjo, S. and Hayami, M. 1987. Structural abnormality and over-expression of the myc gene in feline leukemias. Int. J. Cancer 40: 564-569.

26. Okuda, M., Umeda, A., Sakai, T., Ohashi, T., Momoi, Y., Youn, H. Y., Watari, T., Goitsuka, R., Tsujimoto, H. and Hasegawa, A. 1994. Cloning of feline p53 tumor-suppressor gene and its aberration in hematopoietic tumors. Int. J. Cancer 58: 602-607.

27. Onions, D., Lees, G., Forrest, D. and Neil, J. C. 1987. Recombinant feline viruses containing the myc gene rapidly produce clonal tumours expressing T-cell antigen receptor gene transcripts. Int. J. Cancer 40: 40-45.

28. Orren, D. K., Petersen, L. N. and Bohr, V. A. 1995. A UVresponsive G2 checkpoint in rodent cells. Mol. Cell. Biol. 15: 3722-3730.

29. Pihan, G. A., Purohit. A., Wallace, J., Krecht, H., Woda, B., Quesenberry, P. and Doxsey, S. J. 1998. Centrosome defects and genetic instability in malignant tumors. Cancer Res. 58: 3974-3985.

30. Salisbury, J. L., Whitehead, C. M., Lingle, W. L. and Barrett, S. L. 1999. Centrosomes and cancer. Biol. Cell 91: 451-460.

31. Sarnow, P., Ho, Y. S., Williams, J. and Levine, A. J. 1982. Adenovirus E1b-58kd tumor antigen and SV40 large tumor antigen are physically associated with the same $54 \mathrm{kd}$ cellular protein in transformed cells. Cell 28: 387-394.

32. Setoguchi, A., Okuda, M., Nishida, E., Yazawa, M., Ishizaka, T., Hong, S. H., Hisasue, M., Nishimura, R., Sasaki, N., Yoshikwa, Y., Masuda, K., Ohno, K. and Tsujimoto, H. 2001. Results of hyperamplification of centrosomes in naturally developing tumors of dogs. Am. J. Vet. Res. 62: 1134-1141.

33. Setoguchi, A., Sakai, T., Okuda, M., Minehata, K., Yazawa, M., Ishizaka, T., Watari, T., Nishimura, R., Sasaki, N., Hasegawa, A. and Tsujimoto, H. 2001. Aberrations of the p53 tumor 
suppressor gene in various tumors in dogs. Am. J. Vet. Res. 62: 433-439.

34. Snyder, H. W. Jr., Hardy, W. D. Jr., Zuckerman, E. E. and Fleissner, E. 1978. Characterization of a tumour-specific antigen on the surface of feline lymphosarcoma cells. Nature (Lond.) 275: 656-658.

35. Stearns, T., Evans, L. and Kirschner, M. 1991. Gamma-tubulin is a highly conserved component of the centrosome. Cell $\mathbf{6 5}$ : $825-836$.

36. Stewart, N., Hicks, G. G., Paraskevas, F. and Mowat, M. 1995. Evidence for a second cell cycle block at G2/M by p53. Oncogene 10: 109-115.

37. Tsatsanis, C., Fulton, R., Nishigaki, K., Tsujimoto, H., Levy, L. Terry, A., Spandidos, D., Onions, D. and Neil, J. C. 1994. Genetic determinations of feline leukemia virus-induced lymphoid tumors: patterns of proviral insertion and gene rearrangement. J. Virol. 68: 8296-8303.

38. Vail, D. M. and MacEwen, E. G. 2001. Feline lymphoma and leukemia. pp. 590-611. In: Small Animal Clinical Oncology, 3rd ed., B. W. Saunders, Philadelphia.

39. Wahl, A. F., Donaldson, K. L., Fairchild, C., Lee, F. Y., Foster, S. A., Demers, G. W. and Galloway, D. A. 1996. Loss of normal p53 function confers sensitization to Taxol by increasing G2/M arrest and apoptosis. Nat. Med. 2: 72-79.

40. Weinert, T. and Lydall, D. 1993. Cell cycle checkpoints, genetic instability and cancer. Semin. Cancer Biol. 4: 129-140.

41. Winey, M. 1996. Keeping the centrosome cycle on track. Genome stability. Curr. Biol. 6: 962-964.

42. Wu, F. Y., Iijima, K., Tsujimoto, H., Tamura, Y. and Higurashi, M. 1995. Chromosomal translocations in two feline Tcell lymphomas. Leuk. Res. 19: 857-860.

43. Yew, P. R. and Berk, A. J. 1992. Inhibition of p53 transactivation required for transformation by adenovirus early $1 \mathrm{~B}$ protein. Nature (Lond.) 357: 82-85.

44. Zheng, Y., Jung, M. K. and Oakley, B. R. 1991. Gamma-tubulin is present in Drosophila melanogaster and Homo sapiens and is associated with the centrosome. Cell 65: 817-823. 